\title{
Phase transformation sequence of Ti-6Al-4V as a function of the cooling rate
}

\author{
BUZOLIN Ricardo ${ }^{1,2, a}$, WEISS Desirée ${ }^{1,2, b}$, KRUMPHALS Alfred $^{3, c}$, LASNIK Michael $^{3, d}$, POLETTI Maria Cecilia ${ }^{1,2, e}$ \\ ${ }^{1}$ Christian Doppler Laboratory for Design of High-Performance Alloys by Thermomechanical Processing, Graz, Austria \\ ${ }^{2}$ Institute of Materials Science, Joining and Forming at Graz University of Technology, Graz, Austria \\ 3 voestalpine BÖHLER Aerospace GmbH \& Co KG, Kapfenberg, Austria

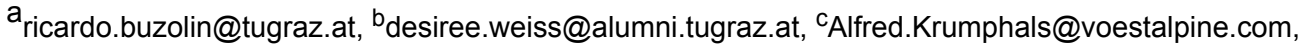 \\ d Michael.Lasnik@voestalpine.com, ${ }^{\mathrm{e}}$ cecilia.poletti@tugraz.at
}

Keywords: Ti-6Al-4V, primary alpha phase, allotriomorphic alpha, materials modelling, continuous cooling.

\begin{abstract}
The growth kinetics of allotriomorphic $\alpha$ along the prior $\beta$ grain boundaries and of globular primary $\alpha$ in Ti-6Al-4V during continuous cooling is described. A physical model is developed based on classical nucleation and growth of platelets for the allotriomorphic $\alpha$. The growth of the primary $\alpha$ is modelled based on the growth of spherical particle immerged on a supersaturated $\beta$-matrix. Continuous cooling tests at two different holding temperatures in the $\alpha+\beta$ field, $930^{\circ} \mathrm{C}$ and $960^{\circ} \mathrm{C}$, and five different cooling rates, $10,30,40,100$ and $300^{\circ} \mathrm{C} / \mathrm{min}$, are conducted to validate the proposed models and elucidate the growth sequence of those $\alpha$ morphologies. Additionally, interrupted tests at different temperatures are conducted to determine the progress of growth of primary $\alpha$ and formation allotriomorphic $\alpha$ during cooling. The size of primary $\alpha$ increases while its size distribution broadens with a decrease in cooling rate. Area fractions of primary $\alpha$ decrease with increasing cooling rate and increasing holding temperature. Moreover, the lower the cooling rate, the thicker the plates of allotriomorphic $\alpha$. At the beginning of the cooling, growth of primary $\alpha$, as well as formation of allotriomorphic $\alpha$ plates is observed. The experimental and modelled results show good agreement.
\end{abstract}

\section{Introduction}

The mechanical properties of Ti-6Al-4V, especially fatigue resistance, toughness and ductility, are strictly correlated with its microstructure formed during the industrial thermo-mechanical treatments [1]. Different microstructures can be achieved, i.e. martensitic, lamellar, equiaxed or bimodal, and they are mainly related to the cooling rate during thermo-mechanical treatment. A bimodal microstructure consisting of lamellar $a$ and globular primary $a\left(a_{p}\right)$ is normally desired owing to the combination of high ductility and high toughness [1]. The globular $a_{p}$ phase grows during cooling, and the allotriomorphic a phase is formed along the grain boundaries.

The growth of $a_{p}$ phase is a diffusion-controlled process. For very slow cooling rates, the $\beta$ phase transformes mainly into $a_{p}$. Thus, the resulting microstructure consists almost entirely of large equiaxed ap with small amounts of retained $\beta$ phase [2]. The amount of $\alpha_{p}$ decreases for increasing cooling rates and other morphologies of a phase are formed [3]. Semiatin et al. [4] observed that $a_{p}$ exhibits epitaxial growth for Ti-6Al-4V, and that it is controlled by the diffusion of vanadium. The presence of a rim- $a$ phase in a near a Ti60 [3] surrounding the $a_{p}$ during cooling with the same crystallographic orientation, evidences the epitaxial growth of $a_{p}$ phase. The nucleation and growth of allotriomorphic $a\left(a_{G B}\right)$ is dependent on the cooling rate and follows a platelet-like formation [2],[4]. Extensions from $a_{p}$ with same crystallographic orientation were observed preferentially along the $\beta / \beta$ boundary suggesting symbiotic growth from the $a_{p}$ phase [3].

Semiatin et al. [4] proposed a model for the growth of ap that uses exact solutions of the diffusion equation and takes into consideration: a) the diffusion coefficients with a thermodynamic correction for the specific composition of the material, and $b$ ) the large super-saturation formed during cooling [4]. Meng et al. [5] complemented the model proposed in [4] by considering the effect of the thermal history on the diffusion field of growing particles, and the overlap of these diffusion fields [6].

The development of robust, accurate but computational simple models to simulate the $\beta \rightarrow a$ transformation are of great importance to predict and control the evolution of the microstructure in complex shape and variable cross sections components during thermomechanical processing. A coupled model for the growth of primary a and formation of allotriomorphic a phases is here proposed. The results are compared with the measured data acquired for different continuous cooling experiments.

\section{Experimental procedures}

\section{Material}

A cogged Ti-6Al- $4 \mathrm{~V}$ in the $\beta$ and $\alpha+\beta$ fields with further annealing at $730^{\circ} \mathrm{C}$ for 1 hour followed by air cooling was used for this investigation. The estimated $\beta$ transus is $\sim 1020^{\circ} \mathrm{C}$ [7]. Cylindrical samples with a diameter of $5.5 \mathrm{~mm}$ and a length $10 \mathrm{~mm}$ were utilized for the heat treatments in a dilatometer.

Table 4: Chemical composition of investigated Ti-6Al-4V [wt.\%] [7]

\begin{tabular}{|c||c||c||c||c||c||c||c||}
\hline $\mathrm{Al}$ & $\mathrm{V}$ & $\mathrm{Fe}$ & $\mathrm{O}$ & $\mathrm{C}$ & $\mathrm{N}$ & $\mathrm{H}$ & $\mathrm{Y}$ \\
\hline \hline 6.54 & 4.21 & 0.20 & 0.185 & 0.028 & 0.023 & 0.000335 & $<0.001$ \\
\hline
\end{tabular}




\section{Heat treatments}

A dilatometer DIL 805A/D (TA Instruments, Hüllhorst, Germany) was used to perform continuous cooling heat treatments. The tests were carried out in a protective atmosphere of argon. After heating with a rate of $30^{\circ} \mathrm{C} / \mathrm{min}$, the samples were held for $1 \mathrm{~h}$ at two different holding temperatures in the $\alpha+\beta$ field, 930 and $960^{\circ} \mathrm{C}$, followed by continuous cooling until room temperature. The cooling was conducted using five different cooling rates: $10,30,40,100$ and $300^{\circ} \mathrm{C} / \mathrm{min}$. Interrupted continuous cooling heat treatments were carried out in order to elucidate the mechanism/s governing the transformation during cooling. After heating with $30^{\circ} \mathrm{C} / \mathrm{min}$, the samples were held for $60 \mathrm{~min}$ at a constant temperature of $930^{\circ} \mathrm{C}$ or $960^{\circ} \mathrm{C}$. The subsequent cooling was performed with 10 and $100^{\circ} \mathrm{C} / \mathrm{min}$. The samples were quenched using Argon at four different temperatures, $900,875,850$ and $800^{\circ} \mathrm{C}$.

\section{Metallography and microstructure investigation}

The samples were polished using OP-S (oxide polishing suspension) after a conventional grinding procedure from grit 500 until 2000 . The samples were etched with Kroll's reagent, $91 \mathrm{ml}$ water, $6 \mathrm{ml} \mathrm{HNO}$ and $3 \mathrm{ml} \mathrm{HF}$. The metallographically prepared and etched samples were investigated using light optical (LOM) and scanning electron (SEM) microscopy. The SEM analysis were conducted using a Tescan Mira3 microscope using an acceleration voltage of $10 \mathrm{kV}$ and working distance of $12 \mathrm{~mm}$. A minimum of five representative micrographs were analysed for each cooling rate and holding temperature for the quantification of globular $a_{p}$. The globular phases were marked using the software GIMP (GNU Image Manipulation Program) and analysed with ImageJ software.

\section{Modelling strategy}

The growth of $a_{p}$ during cooling in heat treatments conducted below the $\beta$-transus temperature was modelled based on [4]. The growth of allotriomorphic a was modelled based on a classical model of nucleation and diffusion equation for growth of platelet. The microstructure is modelled as consisting of three major components: $a_{\mathrm{p}}, a_{\mathrm{SEC}}$ and $a_{\mathrm{GB}}$, as schematically shown in Figure 1. The nucleation and growth of $a_{\mathrm{SEC}}$ is not considered in the present model.
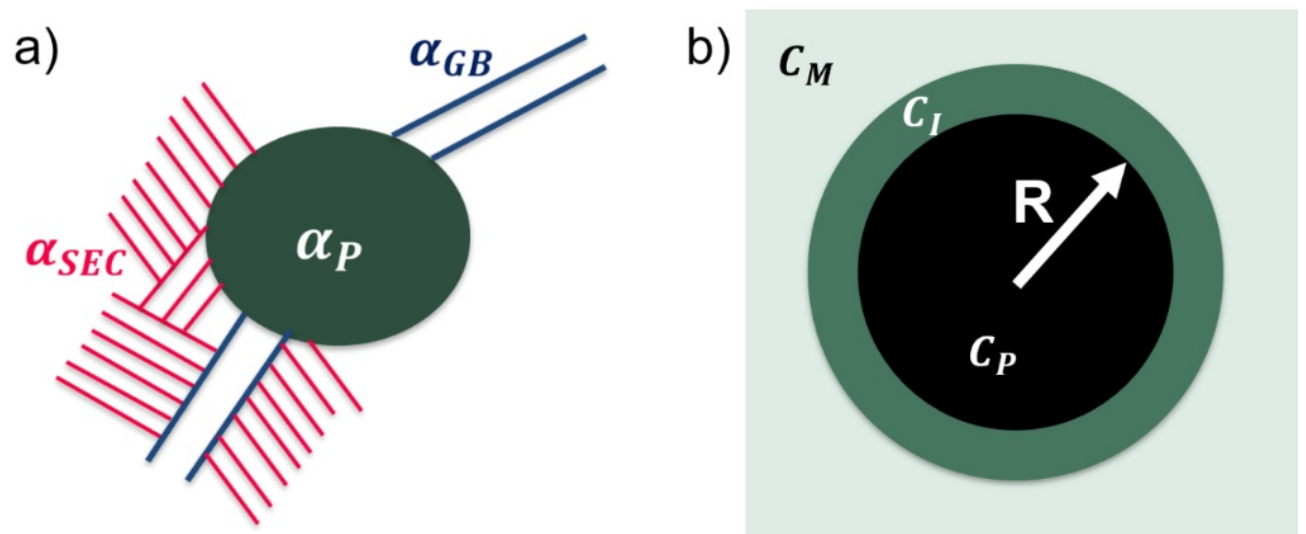

Figure 1: a) Schematic representation of the different morphologies of the alpha phase: primary (ap), secondary ( $\left.a_{S E C}\right)$ and allotriomorphic $\left(a_{G B}\right)$, formed during cooling of a typical Ti-6Al-4V alloy; b) growth of a spherical particle of radius $R$ and composition $C_{P}$ immersed in a matrix of composition $C_{M}$, in which $C_{I}$ is the chemical composition at the interface.

For Ti-6Al-4V Semiatin et al. [4] showed that the growth rate of globular ap phase is limited only by $\mathrm{V}$ diffusion. The intrinsic diffusion coefficient of $\checkmark$ in beta titanium (D) is considered as obtained from Zwicker [8] and also adopted in the model and simulations of Semiatin et al. [4].

The growth of a spherical particle immersed in a matrix of composition $C_{M}$ can be given according to Equation 1 .

$$
\frac{d R}{d t}=2 \lambda^{2} \frac{D}{R}
$$

Where $\mathrm{R}$ is the radius of the particle, $\mathrm{D}$ is the diffusion coefficient and $\lambda$ is a parameter that can be calculated according to Equation 2.

$$
\left\{\lambda^{2} e^{\lambda^{2}}\right\}\left[e^{-\lambda^{2}}-\lambda \sqrt{\pi} \operatorname{erfc}(\lambda)\right]=\Omega / 2
$$

The parameter $\Omega$ denotes supersaturation, and can be calculated according to Equation 3 .

$$
\Omega=\frac{\left(C_{M}-C_{I}\right)}{\left(C_{P}-C_{I}\right)}
$$

Where $C_{1}$ is the composition of the matrix-particle interface, $C_{P}$ is the composition of the $a_{p}$ phase. $C_{M}$ is considered as the equilibrium phase composition of the alloy at the actual temperature, and $C_{p}$ is considered as the equilibrium phase composition of the a phase. The equilibrium phase fraction as well as the chemical composition were calculated using the software JMatPro ${ }^{\circledR} \mathrm{v} .10$. In order to account for the soft impingement on the "far-field" matrix composition, $C_{M}$ is calculated using a usual mass balance between the fraction of a $\left(f_{\alpha}\right)$ and $\beta$ phases, as given by Equation 4. 


$$
C_{M}=\frac{\left(C_{0}-f_{\alpha} C_{\alpha}\right)}{\left(1-f_{\alpha}\right)}
$$

Equation 4

Where $C_{0}$ is the nominal concentration of $V$ in the material and $C_{a}$ is the concentration of $V$ in the a phase. Similar to the growth of $a_{p}$, the partial enrichment of $V$ along the formed $\alpha / \beta$ phase boundary is observed. However, this phenomenon stabilizes locally the $\beta$ phase. Thus, a plate-like morphology of $\alpha$ phase is obtained along the $\beta / \beta$ grain boundaries. When the nucleation time is neglected, the rate of nucleation of precipitates can be given according to Equation 5 .

$$
\frac{d N}{d t}=N_{0}\left(1-f_{\alpha p}-f_{\alpha G B}\right) \exp \left(-\frac{Q}{R T}\right) \exp \left(-\frac{\Delta G_{N u c}^{*}}{R T}\right)
$$

Where $\mathrm{N}_{0}$ is a pre-exponent term and considered as $4.5 \times 10^{4}$ for a prior $\beta$ grain size of $200 \mu \mathrm{m}, \mathrm{Q}$ is the activation energy for diffusion, $\Delta G_{N u c}^{*}$ is the energy barrier for heterogeneous nucleation, $R$ the molar gas constant and $T$ the temperature. $f_{a p}$ and $f_{a G B}$ are the volume fraction of $a_{p}$ and allotriomorphic a formed along the prior beta grain boundaries, respectively. The energy barrier for heterogeneous nucleation can be calculated according to Equation 6.

$$
\Delta G_{N u c}^{*}=-\frac{\left(A^{*}\right)^{3}}{(R T)^{2}\left[\ln \left(\frac{C_{M}}{C_{I}}\right)\right]^{2}}
$$

Where $A^{*}$ is a parameter obtained according to the nucleation at grain boundary, or sympathetic nucleation [9], or a sum of contributions of both (adopted in the current model).

The critical thickness ( $\mathrm{B}_{\mathrm{crit}}$ ) for a disk-like $\mathrm{a}_{\mathrm{GB}}$ to nucleate can be calculated according to Equation 7 .

$$
B_{c r i t}=-\frac{4 \gamma_{\alpha \beta}}{\Delta G_{V}}
$$

Where $\gamma_{\alpha \beta}$ is the interface energy between $\alpha$ and $\beta$ phases, $\Delta G_{V}$ is the chemical free energy of phase transformation obtained using Equation 8 [9].

$$
\operatorname{DeltaG}_{V}=\frac{C_{I}-C_{P}^{\alpha G B}}{1-C_{I}} \frac{R T}{\left(1+\frac{\partial \ln V}{\partial C_{I}}\right)} \ln \left(\frac{C_{I}}{C_{M}}\right)
$$

Where $C_{P}^{\alpha G B}$ is the concentration of $\mathrm{V}$ in the $\mathrm{a}_{\mathrm{GB}}$, considered to be equal to the $\mathrm{V}$ concentration in the $\mathrm{a}_{\mathrm{p}}\left(C_{P}^{\alpha G B}=\mathrm{C}_{\mathrm{p}}\right)$.

The nucleus of $a_{\mathrm{GB}}$ will grow by diffusion process, and it is considered to be similar to the growth of the platelets, i.e. thickening of a planar disordered boundary via ledge growth mechanism. In this case, the lengthening of a platelet is significantly faster than the thickening due to high anisotropy in interfacial energy. Therefore, the volume fraction of $\mathrm{a}_{\mathrm{GB}}$ is only dependent on the number density and its thickness. The thickening of the $\mathrm{a}_{\mathrm{GB}}$ can be then modelled according to Equation 9 .

$$
\frac{d B}{d t}=\frac{2 m \lambda_{G B}^{2} D}{B}
$$

Where $B$ is the thickness of the $a_{G B}$, $m$ is a ledge coefficient to account for the planar disordered growth, $D$ is the diffusivity of $V$ in the $\beta$ matrix and $\lambda_{\mathrm{GB}}$ is parameter that can be calculated according to Equation 10.

$$
\sqrt{\pi} \exp \left(\lambda_{G B}^{2}\right) \operatorname{erfc}\left(\lambda_{G B}\right)=\Omega_{\alpha G B}
$$

Equation 10

Where $\Omega_{\alpha G B}=\left(C_{I}-C_{M}\right) /\left(C_{I}-C_{P}^{\alpha G B}\right)_{\text {is a dimensionless supersaturation parameter, and considered equal to } \Omega \text { because }}$ $C_{P}^{\alpha G B}=C_{P}^{\alpha}$. Similar to the growth of precipitates, the mean thickness of the platelets $(\bar{B})$ is calculated according to Equation 11 [10].

$$
\frac{d \bar{B}}{d t}=\frac{d B}{d t}+\frac{1}{N} \frac{d N}{d t}\left(B_{\text {crit }}-\bar{B}\right)
$$

The first term corresponds to the growth of the existing platelets of allotriomorphic $a$, while the second represents the contribution of new nuclei of critical size calculated according to Equation 7.

A Matlab routine was developed to implement the model for the growth of the ap previously described.

\section{$\underline{\text { Results and discussion }}$}


Figure 2 shows the microstructure of the Ti-6Al-4V argon quenched after $1 \mathrm{~h}$ holding at $960^{\circ} \mathrm{C}$. Sparsely and nearly separated ap particles are found in a matrix of martensite $\left(\alpha^{\prime}\right)$, originally a matrix of $\beta$ phase.

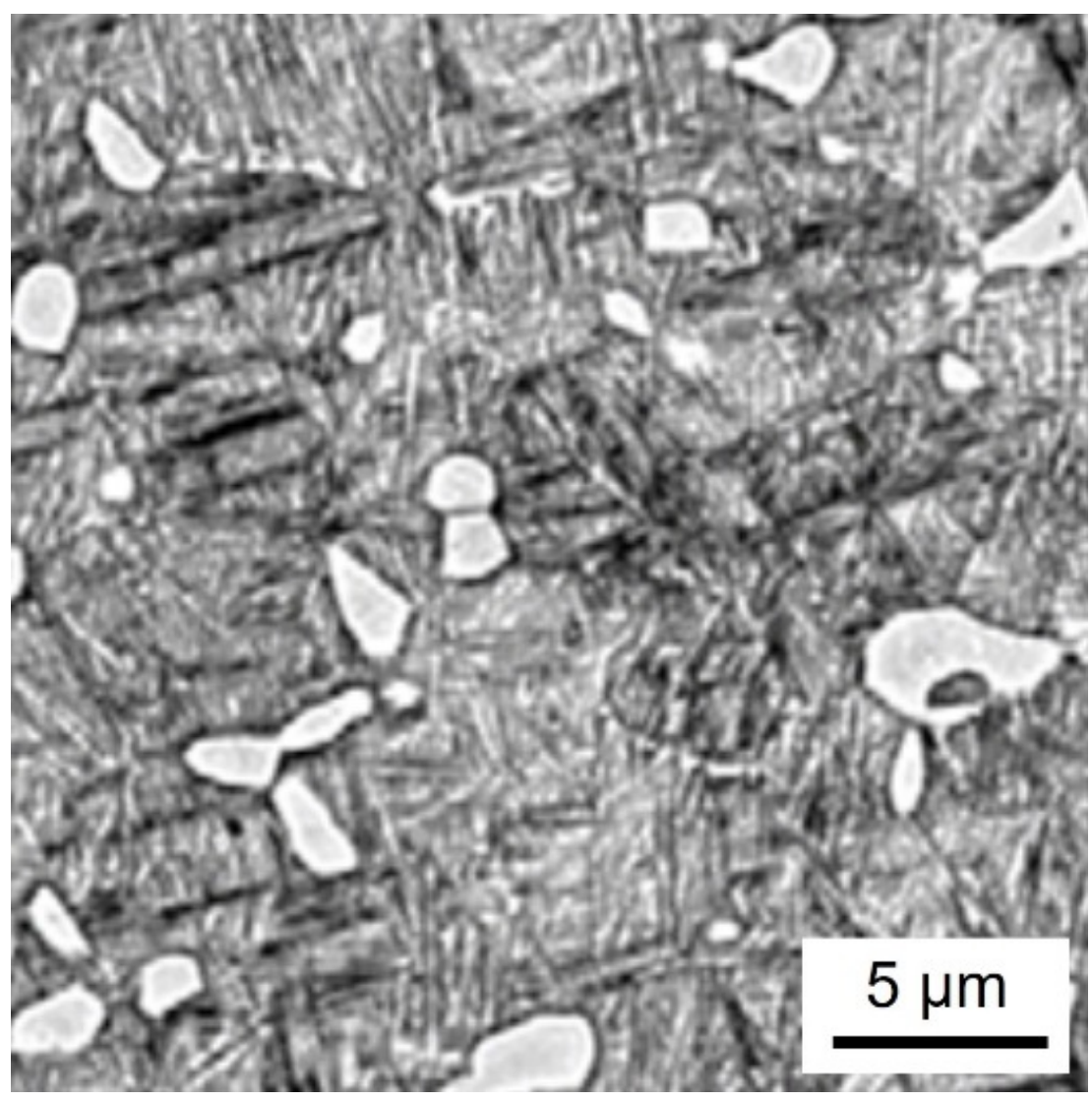

Figure 2: Representative optical micrograph of the investigated Ti-6Al-4V after $1 \mathrm{~h}$ at $960^{\circ} \mathrm{C}$ followed by argon quenching.

From the microstructure shown in Figure 2, different fractions and sizes of a phase are formed during cooling, as shown in Figure 3 . The cooling rate of $10^{\circ} \mathrm{C} / \mathrm{min}$ (Figure $4 \mathrm{a}$ ) lead to a nearly fully equiaxed microstructure, thus mostly growth of $\mathrm{a}_{\mathrm{p}}$ is exhibited. It is difficult to distinguish the lamellas of $a_{\mathrm{SEC}}$ from the globular $a_{\mathrm{p}}$ for the cooling rate of $10^{\circ} \mathrm{C} / \mathrm{min}$. The increase in cooling rate leads to formation of $a_{\mathrm{SEC}}$, as well as $a_{\mathrm{GB}}$ phase. For $30^{\circ} \mathrm{C} / \mathrm{min}$ and $40^{\circ} \mathrm{C} / \mathrm{min}$ (Figure $3 \mathrm{~b}$ and Figure $3 \mathrm{c}$, respectively), $a_{G B}$ exhibits irregularities in the interface surface, as well as the $a_{p}$ phase. Higher cooling rates lead to less pronounced growth of $a_{p}$ and $a_{G B}$ (Figure $3 \mathrm{~d}$ and Figure $3 e$ ). Moreover, regular plate-like morphology of $a_{G B}$ is observed for 100 and $300^{\circ} \mathrm{C} / \mathrm{min}$. 

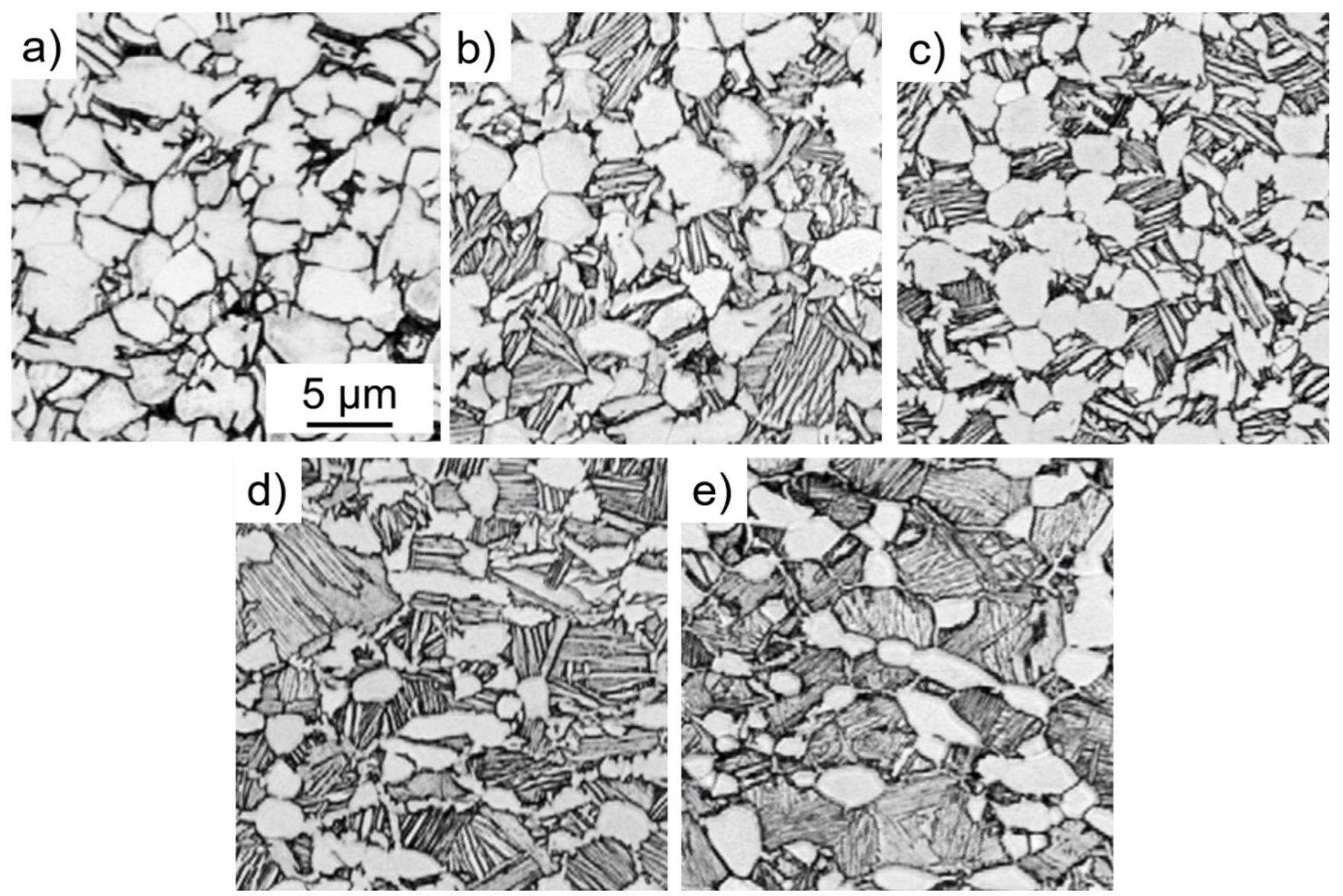

Figure 3: Representative light optical micrographs of the investigated Ti-6Al-4V after holding at $960^{\circ} \mathrm{C}$ for $1 \mathrm{~h}$ followed by continuous cooling at: a) $10^{\circ} \mathrm{C} / \mathrm{min}$; b) $30^{\circ} \mathrm{C} / \mathrm{min}$; c) $40^{\circ} \mathrm{C} / \mathrm{min}$; d) $100^{\circ} \mathrm{C} / \mathrm{min}$; e) $300^{\circ} \mathrm{C} / \mathrm{min}$.

Figure 4 exhibits the typical micrographs after interrupted continuous cooling heat treatments. The $\mathrm{a}_{\mathrm{GB}}$ is highlighted in red dotted line, and the $a_{\mathrm{SEC}}$ in dotted green circles. The formation of $a_{\mathrm{GB}}$ initiates from the globular $a_{p}$, i.e. symbiotic growth. The $2 \mathrm{D}$ interconnectivity of the plates of $a_{\mathrm{GB}}$ along the grain boundaries is very low for $900^{\circ} \mathrm{C}$ (Figure $4(\mathrm{a}, \mathrm{b})$ ). At $850^{\circ} \mathrm{C}$ the grain boundaries are nearly decorated with $\mathrm{a}_{\mathrm{GB}}$. Irregular growth of $\mathrm{a}_{\mathrm{GB}}$ seems to occur at $\sim 800^{\circ} \mathrm{C}$, and is more pronounced for $10^{\circ} \mathrm{C} / \mathrm{min}$ cooling rate (Figure $4 \mathrm{~g}$ ). The nucleation and growth of $\mathrm{a}_{\mathrm{GB}}$ do not seem to be significant at temperatures higher than $900^{\circ} \mathrm{C}$ for the two investigated cooling rates, leading to comparable evolution behaviour of the $\mathrm{a}_{\mathrm{GB}}$ after holding at temperatures of $930^{\circ} \mathrm{C}$ and $960^{\circ} \mathrm{C}$ (Figure $4 \mathrm{a}$ ). Formation of $\mathrm{aSEC}_{\mathrm{SEC}}$ is not pronounced until $850^{\circ} \mathrm{C}$. Although Figure $4 \mathrm{e}$ and Figure $4 \mathrm{~g}$ show the presence of $a_{\mathrm{SEC}}$ for $10^{\circ} \mathrm{C} / \mathrm{min}$ cooling rate, its area fraction is notable small. Similar conclusions can be obtained comparing Figure 3a with Figure $3 d$. 


\section{$10^{\circ} \mathrm{C} / \mathrm{min}$}
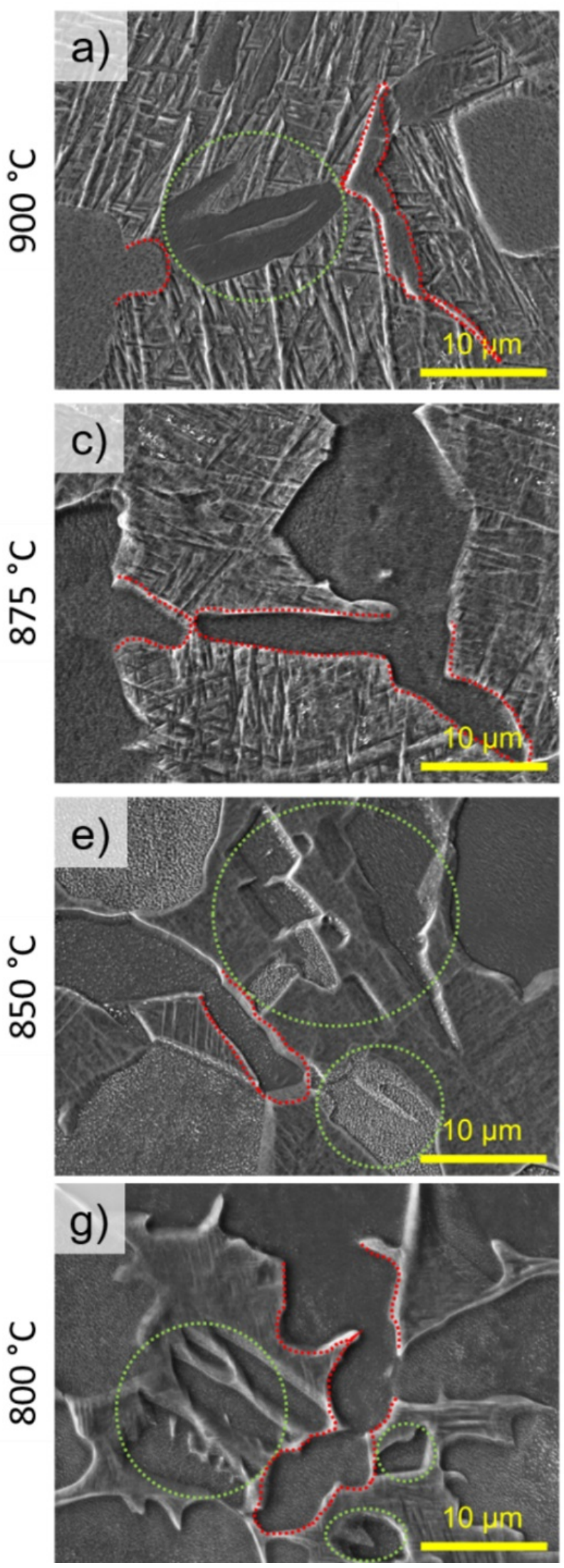

$100^{\circ} \mathrm{C} / \mathrm{min}$
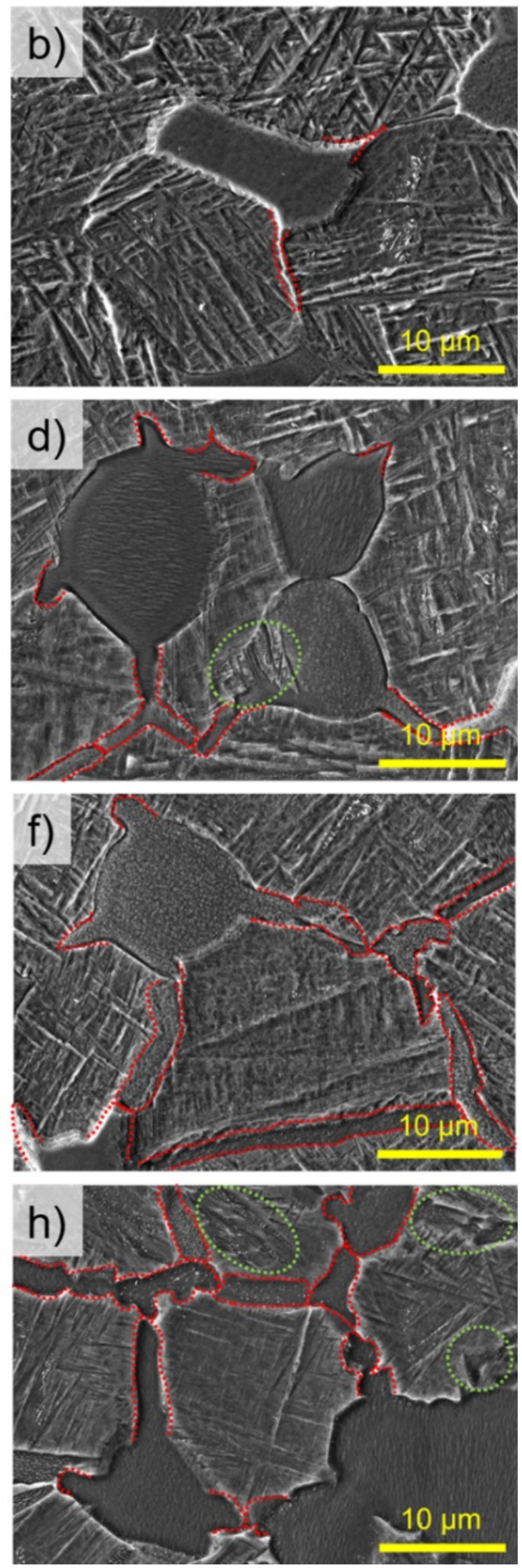

Figure 4: Representative SE-SEM micrographs of the interrupted heat treatments after holding at $960^{\circ} \mathrm{C}$ for $1 \mathrm{~h}$ followed by continuous cooling at $10^{\circ} \mathrm{C} /$ min $(a, c, e, g)$ and $100^{\circ} \mathrm{C} / \mathrm{min}(b, d, f, h)$. The tests were interrupted at: $\left.\left.\left.\left.a, b\right) 900^{\circ} \mathrm{C} ; \mathrm{c}, d\right) 875^{\circ} \mathrm{C} ; e, f\right) 850^{\circ} \mathrm{C} ; g, h\right) 800^{\circ} \mathrm{C}$.

The mean $a_{p}$ diameter, area fraction of $a_{p}$ and the mean thickness of $a_{G B}$ is compared for the simulated and measured results in Figure 5 . The diameter of $a_{p}$ increases with decrease of cooling rate and the model predicts with good accuracy this behaviour. The increase in area fraction of $a_{p}$ is pronounced for decreasing cooling rates. The developed model describes well the area fraction evolution apart from 30 and $40^{\circ} \mathrm{C} / \mathrm{min}$ for 
holding temperature of $960^{\circ} \mathrm{C}$. The thickness of the $\mathrm{a}_{\mathrm{GB}}$ was in the range of $1-4 \mu \mathrm{m}$ for the investigated conditions and it increased with decreasing cooling rates. The differences between $930^{\circ} \mathrm{C}$ and $960^{\circ} \mathrm{C}$ are not significant.

a)

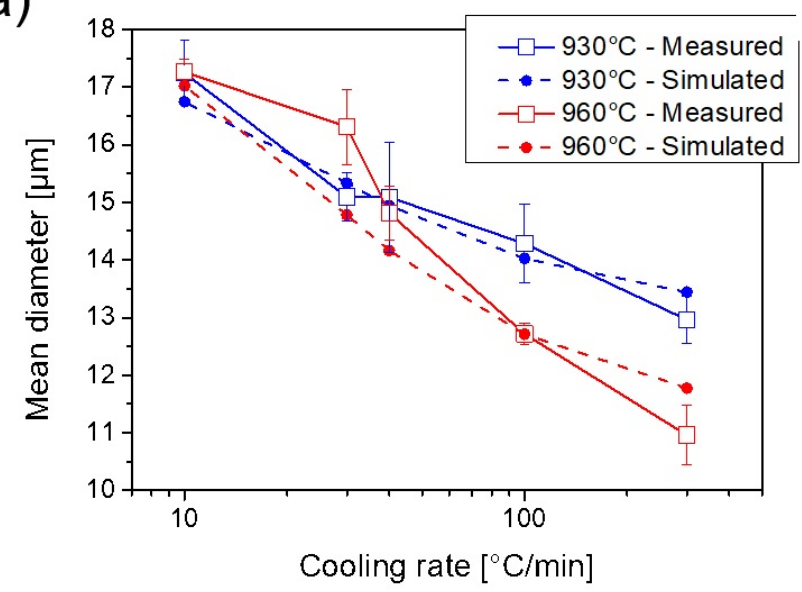

b)

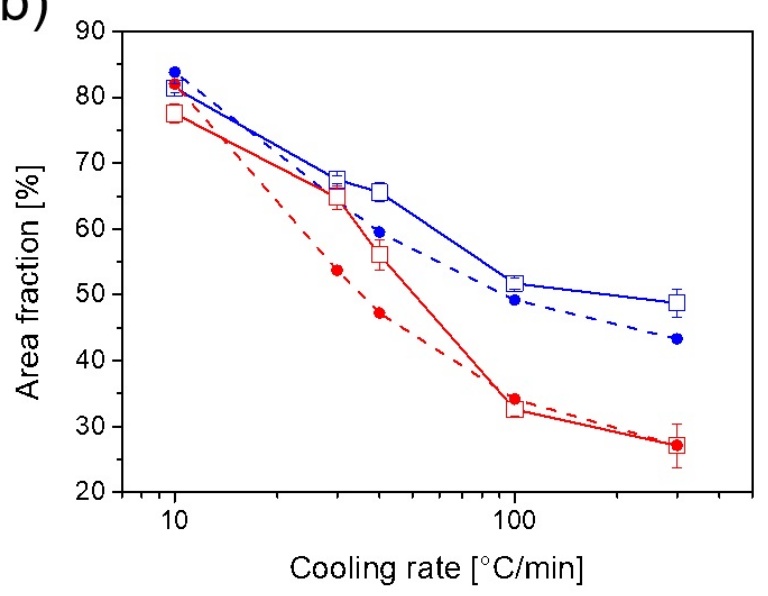

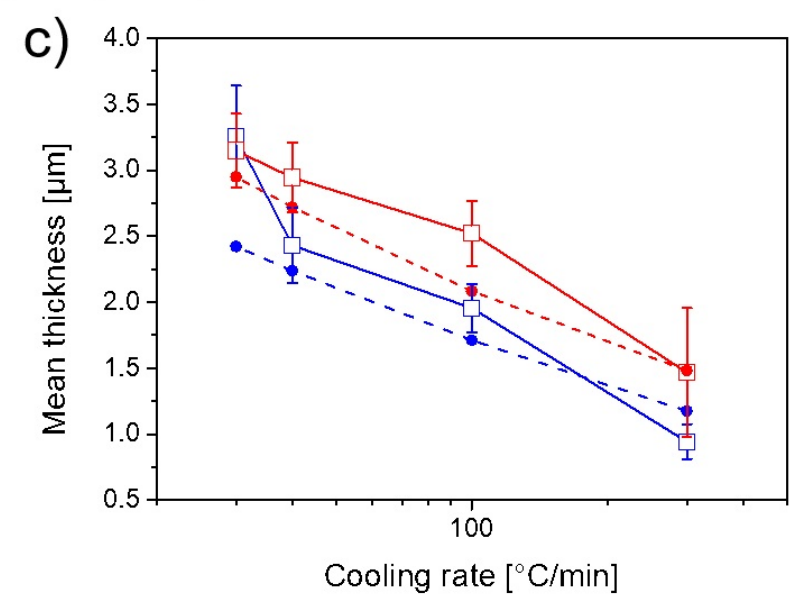

Figure 5: Measured and simulated microstructural features for the investigated cooling rates for the holding temperatures of $930^{\circ} \mathrm{C}$ and $960^{\circ} \mathrm{C}$ : a) mean $a_{P}$ phase diameter, and b) area fraction of $\left.a_{p} ; c\right)$ measured and simulated thickness of the $a_{G B}$

To illustrate the results of the developed model, the evolution of the mean diameter of ap, mean thickness of $a_{\mathrm{GB}}$ and vanadium supersaturation is exhibited in Figure 6 for the holding temperature of $960^{\circ} \mathrm{C}$. A significant growth of $a_{p}$ as well as $a_{G B}$ is predicted down to $800^{\circ} \mathrm{C}$, which was also observed in Figure 4. The supersaturation of $\mathrm{V}$ in $\beta$ phase matrix is predicted to increase sharply until $\sim 850^{\circ} \mathrm{C}$, when the $\alpha_{\mathrm{SEC}}$ is observed to be formed more pronounced (Figure 4). 
a)

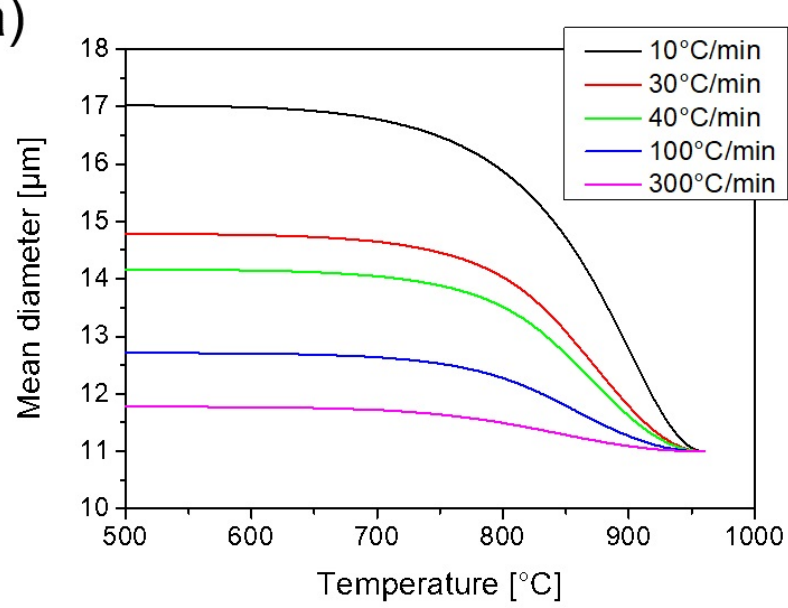

b)

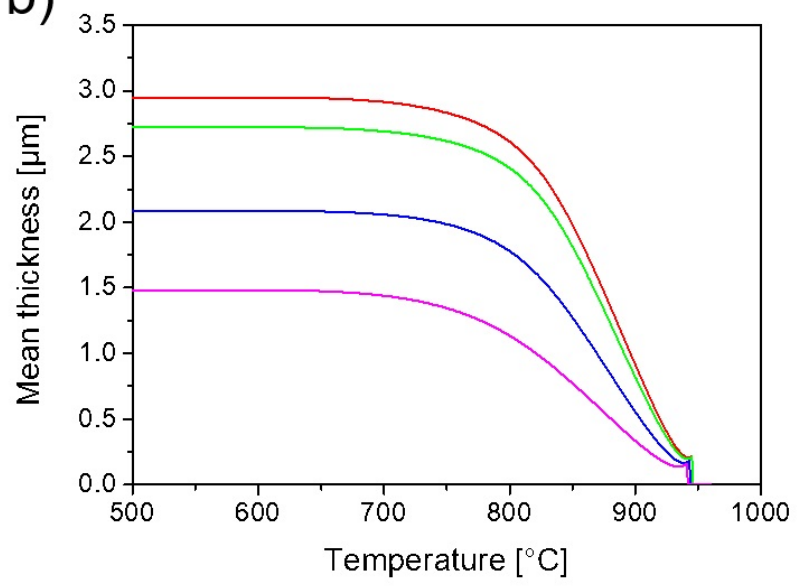

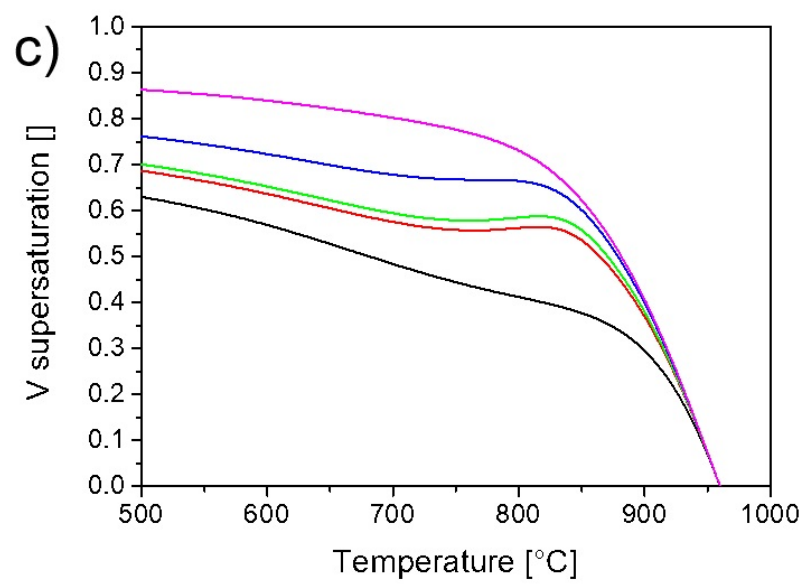

Figure 6: Simulation results for the holding temperature of $960^{\circ} \mathrm{C}: a$ ) mean $a_{P}$ phase diameter; b) mean thickness of the $a_{G B}$; and c) $V$ supersaturation in the $\beta$ matrix evolution.

\section{$\underline{\text { Summary and conclusions }}$}

The sequence of growth of the a phases (primary, secondary and allotriomorphic) during cooling from an isothermal temperature below the $\beta$ transus is clarified and modelled for Ti-6Al-4V. Nucleation of $a_{\mathrm{GB}}$ starts at the globular $a_{\mathrm{p}}$, as well as in other regions. A coupled physical model for the growth of $a_{p}$ phase and the growth of the $a_{G B}$ is developed and the following conclusions can be drawn:

- Growth of $\mathrm{a}_{\mathrm{p}}$ is more pronounced for low cooling rates and occurs more notable until $\sim 800^{\circ} \mathrm{C}$.

- Regular (planar) interface shape of $a_{\mathrm{GB}}$ is observed decorating the prior $\beta$ grain boundaries for high cooling rates. For low cooling rates irregular shapes are observed.

- $a_{\mathrm{GB}}$ nucleates preferentially from existing $a_{\mathrm{p}}$ phase. For higher cooling rates nuclei in triple points and other regions of the prior $\beta / \beta$ grain boundary are observed. The higher nucleation rate for those cooling rates can explain the different behaviour.

- A sharp increase of $\mathrm{V}$ supersaturation in the $\beta$ matrix is observed until $\sim 850^{\circ} \mathrm{C}$, which is attributed to contribute to the formation of $a_{\mathrm{SEC}}$, especially for cooling rates higher than $10^{\circ} \mathrm{C} / \mathrm{min}$.

\section{Acknowledgments}

The authors carried out this work under CD-Laboratory for Design of High-Performance Alloys by Thermomechanical Processing, supported by the Christian Doppler Society.

\section{References}

[1] G. Lütjering and J. C. Williams, Titanium. Berlin, Heidelberg: Springer Berlin Heidelberg, 2007.

[2] R. Pederson, "Microstructure and Phase Transformation of Ti-6Al-4V," pp. 1-62, 2002.

[3] X. Gao, W. Zeng, S. Zhang, and Q. Wang, "A study of epitaxial growth behaviors of equiaxed alpha phase at different cooling rates in near alpha titanium alloy," Acta Mater., vol. 122, pp. 298-309, 2017. 
[4] S. L. Semiatin, S. L. Knisley, P. N. Fagin, F. Zhang, and D. R. Barker, "Microstructure evolution during alpha-beta heat treatment of Ti-6Al-4V," Metall. Mater. Trans. A Phys. Metall. Mater. Sci., vol. 34 A, no. 10, 2003.

[5] M. Meng, H. Yang, X. G. Fan, S. L. Yan, A. M. Zhao, and S. Zhu, "On the modeling of diffusion-controlled growth of primary alpha in heat treatment of two-phase Ti-alloys," J. Alloys Compd., vol. 691, pp. 67-80, 2017.

[6] V. Raghavan, Solid State Phase Transformations. Delhi: PHI Learning Private Limited, 1987.

[7] P. Homporová, "Thermal history of alpha morphology in titanium alloy Ti-6Al-4V," Vienna University of Technology, 2011.

[8] U. Zwicker, Titan und Titanlegierungen. Berlin, Heidelberg: Springer Berlin Heidelberg, 1974.

[9] M. Meng, X. G. Fan, H. Yang, L. G. Guo, M. Zhan, and P. F. Gao, "Precipitation of secondary alpha in competition with epitaxial growth of primary alpha in two-phase titanium alloys," J. Alloys Compd., vol. 714, pp. 294-302, 2017.

[10] A. Deschamps and Y. Brechet, "Influence of predeformation and agEing of an Al-Zn-Mg alloy-II. Modeling of precipitation kinetics and yield stress," Acta Mater., vol. 47, no. 1, pp. 293-305, 1998. 